\title{
Involvement in shared decision-making for patients in public specialist outpatient clinics in Hong Kong
}

\section{Richard $\mathrm{H}$ Xu \\ Eliza LY Wong}

School of Public Health and Primary Care, The Chinese University of Hong Kong, Hong Kong, People's Republic of China
Correspondence: Eliza LY Wong 4/F, School of Public Health and Primary Care, Prince of Wales Hospital, Shatin, New Territories, Hong Kong, People's Republic of China

Email lywong@cuhk.edu.hk
This article was published in the following Dove Press journal:

Patient Preference and Adherence

9 March 2017

Number of times this article has been viewed

Objective: This study is a preliminary exploration of the association between patient involvement in decision-making and patient socioeconomic characteristics and experience in specialist outpatient clinics (SOPCs) in Hong Kong.

Methods: Cross-sectional telephone interviews were conducted using the Specialist Outpatient Experience Questionnaire (SOPEQ) in 26 Hospital Authority public SOPCs in Hong Kong. The SOPEQ was designed by The School of Public Health and Primary Care at The Chinese University of Hong Kong, fully taking into account both literature review and the local context of the public specialist outpatient system in Hong Kong. A total of 22,525 eligible participants were recruited for the study.

Results: There were 13,966 valid responses. The results indicated that the patients who had more involvement in decision-making were younger (odds ratio $[\mathrm{OR}]=2.10 ; 95 \% \mathrm{CI} 1.75,2.53$ ), more highly educated $(\mathrm{OR}=1.67 ; 95 \% \mathrm{CI} 1.45,1.93)$, less likely to be receiving a government allowance $(\mathrm{OR}=0.61 ; 95 \% \mathrm{CI} 0.57,0.65)$, and less likely to be in the new case group $(\mathrm{OR}=0.84$; $95 \%$ CI $0.78,0.92$ ). Participants living with their families (OR $=3.38 ; 95 \%$ CI 2.03, 5.63) or who were unemployed $(\mathrm{OR}=1.10 ; 95 \% \mathrm{CI} 1.01,1.21)$ had a more decisive role in the decisionmaking process. Those participants who had been more involved in decision-making and wanted to continue being more involved had greater levels of satisfaction (mean $=7.94 ; P<0.001$ ) and a better health status (OR $=0.49 ; 95 \%$ CI $0.41,0.58)$.

Conclusion: Engaging patients in their health care management remains a challenge in improving patient-centered care. Our results suggest that patient engagement is associated with perceived health status and the experience of using a health service. Understanding patients' characteristics and roles facilitates the development of preferred styles in the decision-making model.

Keywords: decision-making, doctor-patient relationship, patient engagement, public outpatient setting

\section{Background}

Shared decision-making (SDM) is an essential component of patient engagement that allows patients and their health care providers to discuss each patient's needs, preferences, and treatment options and then make health care decisions together. ${ }^{1}$ The UK was one of the first countries to adopt a policy of promoting SDM and continues to commit to disseminating this model. The latest "Five Year Forward View" of the UK's National Health Service (NHS) continues to stress the importance of increasing patients' direct control over how and where they receive care. ${ }^{2}$ Currently, however, in the majority of clinical encounters, doctors are treated as the best exponent of modern medicine, providing updated treatment options to improve the quality of 
health care and patient outcomes. ${ }^{3}$ Patients are viewed as passive recipients, receiving care only as prescribed by the doctor. ${ }^{4,5}$ As a consequence, patients and their families are excluded from, or are seen to be incapable of, discussing their current health conditions and treatment plans. ${ }^{6}$ The modern change in disease epidemiology from infectious to chronic disease highlights the importance of patient engagement in the doctor-patient relationship. To improve population health, health care professionals must not only manage physical symptoms but also educate, guide, and collaborate with patients to modify lifestyles, prevent disease, and delay or prevent the complications of chronic diseases. ${ }^{7}$ Therefore, in the new health care decade, health is determined not only by the doctor but also by the patient's knowledge, experience, lifestyle, mental condition, and self-management skills in daily life. ${ }^{7}$ The patient who is involved in decision-making thus becomes increasingly important because patients are the ultimate users of health care services.

Engaging patients in decision-making is known to be a dynamic process. In such engagement, patients are treated as active partners with health care professionals in identifying acceptable treatment, management or support options, discussing goals and priorities, and working toward an optimal plan for both patients and health care professionals, all of which ultimately lead to better patient outcomes and health status. ${ }^{8}$ A growing number of studies indicate that the most common sources of patient stress are not being properly informed about health conditions and potentially available choices of treatment and low levels of health literacy. ${ }^{9,10}$ Nearly all patients desire to get as much information as possible from their doctors and to be involved in their own health care through self-management. ${ }^{4,11,12}$ Effective decision coaching, as identified in a series of previous studies, involves developing patient knowledge, raising the awareness of risk aversion, helping patients to choose options based on their preferences, and encouraging patients to be more active in decision-making with health care professionals in various settings. ${ }^{13,14}$ In addition, considerable evidence suggests that patient engagement should be tailored to an individual's needs because different patients have different expectations, preferences, and concerns. ${ }^{15}$ The crucial step in facilitating patient engagement in decision-making is to identify individual or population characteristics and outline those features that influence patients' preferences and decision-making styles. However, there is always a significant difference between the role the patient expects to play and that actually played in the clinical context. ${ }^{16}$ Each year, 24 million outpatient visits are made to medical clinics in Hong Kong's dual-track health system, ${ }^{17}$ but to date, no study has attempted to explore patient experiences in the decision-making process during such visits. ${ }^{10}$ This study aims to investigate the association between patient involvement in decision-making and patient socioeconomic characteristics, satisfaction with health care, and health status in the public outpatient setting of Hong Kong. The findings should provide valuable input to guide the development of patient engagement and patient-centered care.

\section{Methods}

\section{Data collection}

A territory-wide cross-sectional telephone survey was conducted in all public specialist outpatient clinics (SOPCs) in Hong Kong between July and December 2014. The inclusion criteria were as follows: Hong Kong citizens with Hong Kong identity cards, age $\geq 18$ years, and attendance at one of the 26 Hospital Authority SOPCs between July and November 2014. Those meeting the inclusion criteria were approached for a telephone interview within 48 hours to 1 month of attending an SOPC. The exclusion criteria were as follows: those patients who were unable to understand or speak Cantonese, day-case or day-survey patients, and patients attending the following types of SOPC: pediatric, hospice, psychiatric, dental, anesthetic, pathology, nurse-led, and multispecialty outpatient clinics. Ethical approval was obtained from the Clinical Research Ethics Committee of The Chinese University of Hong Kong. Verbal consent was sought before interview, and all the respondents were fully informed of their rights, the purpose of the study, and the data collection procedure.

\section{Study instrument}

Our survey was based on the Specialist Outpatient Experience Questionnaire (SOPEQ) and designed and validated by The School of Public Health and Primary Care at The Chinese University of Hong Kong. The SOPEQ uses rigorous and mixed methodology derived from a series of qualitative and quantitative studies with excellent reliability and validity. ${ }^{18}$ It provides a representative picture of patient experience through following the patient journey in the specialist outpatient service from "before the appointment" to "leaving the clinic", using 48 evaluative items covering 10 care aspects to evaluate patient experience and satisfaction. Involvement in decision-making is an essential item in the survey.

\section{Data analysis}

Data management and analysis were performed using SPSS Version 21.0. The demographics of the respondents and the response profiles were presented descriptively. 
Analysis of variance (ANOVA) models were used to analyze patient satisfaction for different groups of patients. Logistic regression models were used to estimate the crude odds ratio of evaluative items related to involvement in decision-making, and $95 \%$ confidence intervals controlled for the covariates of age, gender, educational level, case group, government allowance, current health status, and working and living statuses. Linear regression models were used to test the relationship between patient decision-making and patient satisfaction.

\section{Results}

\section{Demographics}

In total, 22,525 patients were approached to participate in the study. It was noted that during the study period, a relatively small proportion of the respondents lived in elderly care homes in comparison with the overall study population. Of the eligible patients, 13,966 patients responded with a fully completed survey questionnaire, with a response rate of $62 \%$. The majority of the respondents were female $(57.5 \%)$, old cases (79.5\%), aged $>61$ years $(50 \%)$, and of a lower level of education ( $>80 \%$ lower than secondary level). More than half of the respondents (53.7\%) had long-term conditions, of whom $92.6 \%$ had the most common chronic diseases. Employed respondents amounted to $40 \%$, followed by retired respondents $(36.6 \%)$. The vast majority of the respondents lived with their families (94\%) (Table 1).

\section{Patient engagement}

Patients in the age group of 41-60 years (62.9\%) reported the highest rate of involvement in decision-making, with significantly higher involvement in decision-making, than those in the oldest group ( $\mathrm{OR}=1.56 ; 95 \%$ CI 1.48, 1.68). Patients with tertiary-level education (62.9\%) also reported the highest rate of involvement in decision-making. The study found that the higher the level of education, the better the involvement in patient-doctor encounters; and vice versa. Similarly, patients with a chronic illness were more likely to be involved in the decision-making process, whereas those presenting as new cases were found to be less involved in patient-doctor engagement ( $\mathrm{OR}=0.84 ; 95 \%$ CI $0.78,0.92$ ). Those who were retired showed the least interest in getting involved in clinical decision-making compared with the other groups. Those who were unemployed were similar to other groups regarding being involved in decision-making ( $\mathrm{OR}=1.10 ; 95 \%$ CI 1.01, 1.21). Those receiving a government allowance (30\% of responders) were less likely to be involved in decision-making than nonreceivers (Table 2), regardless of the type of allowance.
Table I Distribution of respondents' socioeconomic status

\begin{tabular}{|c|c|c|c|c|c|c|c|}
\hline \multirow[t]{2}{*}{ Variable } & \multirow[t]{2}{*}{$N=13,966$} & \multirow[t]{2}{*}{$\%$} & \multicolumn{4}{|c|}{$\begin{array}{l}\text { Involved in } \\
\text { decision-making }\end{array}$} & \multirow[t]{2}{*}{$P$-value } \\
\hline & & & Yes & $\%$ & No & $\%$ & \\
\hline Gender & & & & & & & 0.14 \\
\hline Male & 5,936 & 42.5 & 3,424 & 57.7 & 2,512 & 42.3 & \\
\hline Female & 8,030 & 57.5 & 4,588 & 57.1 & 3,442 & 42.9 & \\
\hline Case group & & & & & & & $<0.001$ \\
\hline New case & 2,869 & 20.5 & $|, 55|$ & 54.1 & 1,318 & 45.9 & \\
\hline Old case & II,097 & 79.5 & 6,461 & 58.2 & 4,636 & 41.8 & \\
\hline Age group (years) & & & & & & & $<0.001$ \\
\hline $18-40$ & 2,000 & 14.3 & 1,199 & 59.9 & 801 & 40.1 & \\
\hline $4 I-60$ & 5,294 & 37.9 & 3,332 & 62.9 & 1,962 & 37.1 & \\
\hline$\geq 6 \mathrm{I}$ & 6,672 & 47.8 & 3,481 & 52.2 & 3,191 & 47.8 & \\
\hline Education $^{\mathrm{a}, \mathrm{b}}$ & & & & & & & $<0.001$ \\
\hline No education & 1,330 & 9.6 & 670 & 50.4 & 660 & 49.6 & \\
\hline Primary & 3,745 & 26.9 & 1,956 & 52.2 & I,789 & 47.8 & \\
\hline Secondary & 6,127 & 44.I & 3,697 & 60.3 & 2,430 & 39.7 & \\
\hline Postsecondary & 904 & 6.5 & 529 & 58.5 & 375 & 41.5 & \\
\hline Tertiary or above & $\mathrm{I}, 794$ & 12.9 & 1,129 & 62.9 & 665 & 37.1 & \\
\hline Receive government & allowance & & & & & & $<0.001$ \\
\hline Yes & 4,217 & 30.2 & 2,060 & 48.8 & 2,157 & 51.2 & \\
\hline No & 9,749 & 69.8 & 5,952 & 61.1 & 3,797 & 38.9 & \\
\hline Current living status & & & & & & & $<0.001$ \\
\hline Live alone & 716 & 5.1 & 336 & 46.9 & 380 & 53.1 & \\
\hline $\begin{array}{l}\text { Live with family/ } \\
\text { others }\end{array}$ & 13,125 & 94.0 & 7,638 & 58.2 & 5,487 & 41.8 & \\
\hline Live in institution ${ }^{c}$ & 72 & 0.4 & 21 & 28.6 & 51 & 71.4 & \\
\hline Refuse to answer & 53 & 0.4 & 17 & 32.1 & 36 & 67.9 & \\
\hline Current work status & & & & & & & $<0.001$ \\
\hline Retired & 5,125 & 36.7 & 2,601 & 50.8 & 2,524 & 49.2 & \\
\hline Unemployment $^{\mathrm{d}}$ & 3,136 & 22.5 & 1,968 & 62.8 & 1,168 & 37.2 & \\
\hline Employment $^{\mathrm{e}}$ & 5,645 & 40.4 & $3,4 I I$ & 60.4 & 2,234 & 39.6 & \\
\hline Refuse to answer & 60 & 0.4 & 32 & 53.3 & 28 & 46.7 & \\
\hline Having longstanding $c$ & condition & & & & & & $<0.001$ \\
\hline Yes & 7,495 & 53.7 & 3,980 & 53.1 & 3,515 & 46.9 & \\
\hline No & 6,471 & 46.3 & 4,032 & 62.3 & 2,439 & 37.7 & \\
\hline
\end{tabular}

Notes: ${ }^{\mathrm{N} o}$, no formal education/kindergarten, secondary included lower secondary $=$ S.I-S.3 and upper secondary = S.4-S.5, and postsecondary included postsecondary and matriculation $=\mathrm{S} .6-\mathrm{S} .7$. ${ }^{\mathrm{b}}$ There are 66 subjects who refused to answer, the total response of education is 13,900 . 'Convalescent hospital/rehabilitation hospital/ hospital and old age home. dUnemployment included unemployed, home maker, and full-time student. ${ }^{~}$ Employment included full-time worker and part-time worker. Abbreviation: S, secondary.

Patients living alone $(\mathrm{OR}=2.15 ; 95 \% \mathrm{CI} 1.24,3.64)$ or with their family (OR $=3.38 ; 95 \% \mathrm{CI} 2.03,5.63)$ were more likely to be involved in decision-making than patients living in an institution. Those living in an institution had the lowest rate (28.6\%) of involvement in decision-making compared with those living in the community (living alone or living with family) ( $\mathrm{OR}=0.86 ; 95 \% \mathrm{CI} 0.81,0.91)$.

\section{Correlation between patient engagement and experience of health service and health outcomes}

Table 3 shows the results for two models that separately tested the relationship between patient decision-making and 
Table 2 Predictors of patients' involvement to make decision in univariate analysis

\begin{tabular}{|c|c|c|c|c|}
\hline Variable & Coefficient & OR & $\begin{array}{l}95 \% \mathrm{Cl} \\
(\mathrm{OR})\end{array}$ & $P$-value \\
\hline \multicolumn{5}{|l|}{ Gender } \\
\hline Male & 0.022 & 1.02 & $0.96-1.09$ & 0.52 \\
\hline Female & & 1 & & \\
\hline \multicolumn{5}{|l|}{ Case group } \\
\hline New case & -0.169 & 0.84 & $0.78-0.92$ & $<0.001$ \\
\hline Old case & & I & & \\
\hline \multicolumn{5}{|l|}{ Age group (years) } \\
\hline $18-40$ & 0.316 & 1.37 & $1.24-1.52$ & $<0.001$ \\
\hline $4 I-60$ & 0.443 & 1.56 & $1.45-1.68$ & $<0.001$ \\
\hline$\geq 6 \mathrm{I}$ & & 1 & & \\
\hline \multicolumn{5}{|l|}{ Education } \\
\hline No education & -0.513 & 0.59 & $0.51-0.69$ & $<0.001$ \\
\hline Primary & -0.442 & 0.64 & $0.57-0.72$ & $<0.001$ \\
\hline Secondary & -0.114 & 0.89 & $0.80-0.99$ & 0.04 \\
\hline Postsecondary & -0.185 & 0.83 & $0.7 I-0.98$ & 0.02 \\
\hline Tertiary or above & & I & & \\
\hline \multicolumn{5}{|c|}{ Allowance from government } \\
\hline Yes & -0.496 & 0.61 & $0.57-0.65$ & $<0.001$ \\
\hline No & & I & & \\
\hline \multicolumn{5}{|l|}{ Current living status } \\
\hline Live alone & 0.764 & 2.15 & $1.24-3.64$ & 0.005 \\
\hline Live with family/others & 1.218 & 3.38 & $2.03-5.63$ & $<0.001$ \\
\hline Live in institution ${ }^{\mathrm{a}}$ & & 1 & & \\
\hline \multicolumn{5}{|l|}{ Current work status } \\
\hline Retired & -0.393 & 0.67 & $0.62-0.73$ & $<0.001$ \\
\hline Unemployment & 0.099 & 1.10 & $1.01-1.21$ & 0.03 \\
\hline Employment ${ }^{\mathrm{b}}$ & & 1 & & \\
\hline \multicolumn{5}{|c|}{ Having longstanding condition } \\
\hline Yes & -0.378 & 0.68 & $0.64-0.73$ & $<0.001$ \\
\hline No & & I & & \\
\hline
\end{tabular}

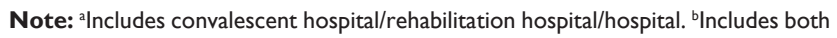
full-time and part-time.

Abbreviations: $\mathrm{Cl}$, confidence interval, OR, odds ratio. patient satisfaction and between patient decision-making and self-reported health status. Patients who were involved in decision-making and wanted more involvement had a higher mean score for satisfaction than other groups (mean $=7.94$; $P<0.001)$; those patients who were not involved and did not want to be involved had the lowest mean score (mean $=7.11$; $P<0.001)$. In model 2 , the results for the correlation between decision-making and health status were similar to those in model 1. The patients who were involved in decisionmaking and wanted more involvement had a better selfreported health status than other groups (OR $=0.49 ; 95 \%$ CI $0.41,0.58)$, and those who were not involved and did not want to be involved reported worse health status $(\mathrm{OR}=1.51$; $95 \%$ CI $1.25,1.81)$.

\section{Discussion}

Our study is the first large, population-based survey in Hong Kong to evaluate people's attitudes toward involvement in clinical decision-making. Many associations of patient decision-making with socioeconomic context and health, working, and living statuses were found and confirmed first in the local environment. Approximately $60 \%(8,012 / 13,966)$ of the survey respondents reported having been involved in decision-making once or more than once, which is lower than for Japan, the US, and Canada.. ${ }^{919}$ Despite the existence of policies that encourage patients to be more involved in selfmanagement and clear evidence of benefit, engagement in decision-making remains lower than desired. The experience of, and willingness to be involved in, decision-making shows considerable pluralism within various socioeconomic groups.

Table 3 The relationship among patients' attitude to be involved in decision-making, health status, and satisfaction

\begin{tabular}{|c|c|c|c|c|c|c|c|c|c|c|c|}
\hline \multirow[t]{2}{*}{ Variable } & \multicolumn{5}{|c|}{ Model I, patient's satisfaction } & \multicolumn{6}{|c|}{ Model 2, self-reported health status } \\
\hline & Mean & $P$-value & B & $95 \% \mathrm{Cl}$ & $P$-value & Good, n & Poor, n & Coefficient & OR & $95 \% \mathrm{Cl}$ & $P$-value \\
\hline Constant & & & 7.412 & $7.36-7.47$ & $<0.001$ & & & -2.215 & & & $<0.001$ \\
\hline $\begin{array}{l}\text { Involved and } \\
\text { wanting less } \\
\text { involvement }\end{array}$ & 7.37 & $<0.001$ & & & & 3,235 & 353 & & I & & \\
\hline $\begin{array}{l}\text { Involved and } \\
\text { wanting more } \\
\text { involvement }\end{array}$ & 7.94 & & & & & 4,199 & 225 & -0.711 & 0.49 & $0.4 I-0.58$ & $<0.001$ \\
\hline $\begin{array}{l}\text { Not involved } \\
\text { and not } \\
\text { wanting to be } \\
\text { involved }\end{array}$ & 7.11 & & & & & 1,198 & 197 & 0.410 & 1.51 & $1.25-1.81$ & $<0.001$ \\
\hline $\begin{array}{l}\text { Not involved } \\
\text { but wanting } \\
\text { to be involved }\end{array}$ & 7.93 & & & & & 4,149 & 410 & -0.099 & 0.91 & $0.78-0.99$ & $<0.05$ \\
\hline
\end{tabular}

Abbreviations: $\mathrm{Cl}$, confidence interval; OR, odds ratio. 
Health care professionals thus need to understand patients' backgrounds, desires, and preferred roles in the decisionmaking process so as to maximize positive experiences in the health care journey. However, our study showed that initiatives to empower patients are still performing poorly, at least in mainstream clinical practice.

Although the majority of the patients surveyed had high expectations of being involved in the decision-making process, they were not encouraged to share their perceptions, beliefs, and preferences in a timely manner by their health care professionals. The study further highlighted that patients in the old case group were significantly more likely to be involved in decision-making than those in the new case group, which agrees with the findings of most previous studies. $^{20,21}$ This implies that patient involvement requires sufficient time for building a relationship with health care professionals and adapting to a "patient" role in self-management. Butow et $\mathrm{al}^{20}$ indicated that changes in patients' attitudes and preferences may be attributed to the exacerbation or resolution of their illness and whether the doctor's performance met the patient's expectations, which may not be the only reason why patient involvement seems to change gradually. ${ }^{20,22}$

Our findings suggest that the age-education relationship has a significant influence on involvement in decision-making. Young people with a higher level of education appear to be more likely to be involved in decision-making than their older counterparts. A previous study also found that compared with the previous generation, young people are more confident, better educated, and more adept at seeking state-of-the-art information and using advanced medical devices, which may help them to understand and monitor their health conditions in more efficient and effective ways. However, Hong Kong's health care system may fail to detect the various needs of patients of different ages and with differing literacy. ${ }^{23}$ The National Cancer Equality Initiative in the USA also reported that chronological age alone was significant in influencing clinical decision-making, something that clinicians apparently did not consciously recognize. ${ }^{24}$

Government allowance is a term commonly and traditionally used to describe a particular financial situation of a patient. ${ }^{23,25}$ However, to the best of our knowledge, research into the association between patient decision-making and government allowance is scanty. In our study, those receiving a government allowance were less likely to have been involved in decision-making in the past. The majority of government allowance receivers in Hong Kong belong to lesser educated, poor, disabled, and unemployed populations and socially vulnerable groups with a lower sense of social belonging, self-responsibility, and confidence. Ford et $\mathrm{al}^{26}$ indicated that a reduced sense of responsibility is an essential barrier to developing a trusting partnership with a doctor and that the lack of confidence affects a patient's willingness to be involved in decision-making. ${ }^{27-29}$ We suggest that a government allowance could be either a positive or a negative incentive to steer providers and patients away from more costly treatments with unproven benefits and toward reasonable and evidence-based treatment options.

Involvement of families and dependents is typically identified by patients as an important indicator of good

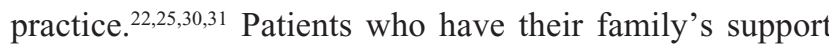
and encouragement are inclined to be more confident and optimistic when they discuss their health conditions and treatment plan with their caregivers. ${ }^{12,32,33}$ A study has confirmed that family members can help patients to have better physical comfort, more efficient pain management, greater emotional support, and improved alleviation of fear and anxiety. ${ }^{6}$ Conversely, due to a lack of understanding regarding patients' values, preferences, and needs, people living in elderly care homes are less involved in decision-making for their health. Elwyn et al indicated that although the residents of institutions demonstrated a desire to be more involved in their health management, most felt that it was stressful trying to understand the explanations of professionals when they had no family support in the context of the residential environment and they consequently felt less empowered and engaged. The residents were thus unable and reluctant to become involved in the decision-making process. ${ }^{34}$ Although the importance of patient engagement is very clear, in practice, the design, implementation, and evaluation required to position patients as partners in the delivery of health care services are absent. ${ }^{35}$

Working status also has an interesting relationship with patient's involvement in decision-making. The unemployed group, surprisingly, were more likely to get involved in decision-making than other groups, a finding that coincides with the results of a previous NHS survey. ${ }^{36}$ In our view, those without jobs typically have heavier socioeconomic burdens and, due to a lack of medical insurance, their proactive involvement in decision-making may thus stem merely from a wish to save money by pushing doctors to make a relatively simple diagnosis and prescribe inexpensive medicines. ${ }^{29}$ Moreover, those who are temporarily unemployed or positively unemployed (changing to another job) 
may not be associated with strong economic pressure or lower educational performance. The choices of these people may confuse the results and need further elaborative study.

Patients need to be confident that their providers and health care system will provide safe and high-quality services when these are needed. Our findings are in agreement with those of previous studies conducted in the UK and USA, in that actual experience of involvement in decision-making is an important factor in patient satisfaction. ${ }^{37,38}$ To support the future design of SDM interventions and to fill the gaps in our current knowledge, we have analyzed the patients' responses in terms not only of involvement in decision-making but also of willingness to be involved in the future. Interestingly, we found a strong correlation between patients' perceptions of being involved in decision-making and their satisfaction, whether they were involved or not. This finding may support the contention that a long-term positive effect of involving patients in decision-making is to improve patient satisfaction and experience with health care services. However, achieving long-term improvements in health quality is a complicated process that is also associated with other factors, such as effectiveness, communication with patients, respect for patient dignity and preferences, and information relating to potential harm after discharge.

In our study, people's health status was found to be an important indicator of the effect of involving patients in decision-making. Other studies worldwide have also found that both inpatients' and outpatients' life quality, medication use, and readmission rates were significantly related to their reported involvement in decision-making. ${ }^{39,40}$ Our results indicate that a patient who has not been involved in decision-making and does not want to be involved in the future has a worse health status than other patients. This finding is partly consistent with those of previous studies that found that patients who are in a critical condition or have long-term mental illness tend to be less interested in being involved in their own health control and management. Conversely, patients who have better health status are typically very willing to be involved in decision-making and become more confident regarding communicating with their providers about their values, preferences, and concerns when they have had satisfactory experiences of being involved in decision-making in the past. Our results also suggest that if we wish to improve patients' health status, it is not sufficient merely to involve patients in decision-making now; they must also be continually inspired to increase the awareness of the importance of engaging in decision-making in the long run. Moreover, health professionals should also be encouraged to provide more easily understood information and to empower patients with greater autonomy to make decisions. Bogardus et $\mathrm{al}^{41}$ indicated that improvements in patients' health due to their involvement in decision-making are as quantifiable as those due to many drugs.

Our study has a number of possible limitations. As the setting of our study was outpatient clinics only, patients' experiences of decision-making in acute and emergency departments and as inpatients are not clear. Insurance coverage is a useful indicator of patient decision-making, but private insurance coverage was not investigated in the study. Some recall bias may exist due to longer time lags between patients receiving services and our survey. Another limitation is that we conducted only a cross-sectional study. As patient preferences may develop and change over time or as physical, psychological, or life situations change, our survey can demonstrate only associations and not show causality. A final limitation is the absence of face-to-face communication, which makes it more difficult to establish a relationship of trust with respondents and may lead to a degree of collective information bias.

The majority of developed economies recognize that SDM is a central goal of health care system reform in response to the wishes of patients and their families to be more involved in health control and management, and considerable evidence exists that active patient engagement is associated with superior clinical outcomes. To date, however, Hong Kong has put little stress on this important area. ${ }^{6,16,42,43}$ Although the Hong Kong government demonstrates a high degree of interest through its policies, efforts to position patients at the center of health care services have met with much resistance in real-world contexts. Our survey, one of the first such studies in Hong Kong, provides a baseline for evaluating patient involvement in decision-making by controlling for various characteristics and allowing greater comparison between different regions and between both local and global settings.

\section{Implications for clinical practice}

The study indicates that the majority of patients are keen to engage or be engaged in interactions with doctors. Doctors and other health care professionals, such as nurses and clinical pharmacists, need to support and identify measures that can enhance patients' level of engagement while taking into consideration their different social and health backgrounds. In addition to a patient's literacy, age, and disease prognosis, involvement of a patient's caregiver is also important to enable the patient to interact with the doctor. The findings 
of the study may provide valuable input for health policy makers, managers, and health care professionals planning appropriate strategies to improve patient engagement and move forward to patient-centered care.

\section{Conclusion}

SDM is a complicated and multifaceted but meritorious intervention that incorporates patients' priorities, preferences, and values into improving their health and health care. It is important to investigate and respect patients' culture and social background before implementing health-promoting strategies. The shift to SDM begins with increased awareness among patients, families, representatives, and professionals at various levels - direct care, organizational, and policy making - that patients should be positioned at the core of good clinical practice and at the center of all decisions. ${ }^{44}$ Our study first investigates and confirms several relationships between Hong Kong patients' perceptions regarding involvement in decision-making and their socioeconomic and health characteristics, which provide valuable and meaningful insights for hospital administrators, researchers, and front-line professionals aiming to fully understand and consider patients' roles and feelings regarding clinical decision-making and to design the style of decision-making preferred by patients. It also lays a solid foundation for the future study of patient engagement.

\section{Author contributions}

Both authors contributed toward data analysis, drafting and critically revising the paper and agree to be accountable for all aspects of the work.

\section{Disclosure}

The authors report no conflicts of interest in this work.

\section{References}

1. Murray E, Pollack L, White M, Lo B. Clinical decision-making: patients' preferences and experiences. Patient Educ Couns. 2007;65(2): 189-196.

2. National Health Services [webpage on the Internet]. Five Year Forward View; 2014. Available from: http://www.england.nhs.uk/ourwork/futurenhs/. Accessed February 15, 2016.

3. Sullivan M. The new subjective medicine: taking the patient's point of view on health care and health. Soc Sci Med. 2003;56(7):1595-1604

4. Dahlberg K, Todres L, Galvin K. Lifeworld-led healthcare is more than patient-led care: an existential view of well-being. Med Health Care Philos. 2009;12(3):265-271.

5. Montori VM, Gafni A, Charles C. A shared treatment decision-making approach between patients with chronic conditions and their clinicians: the case of diabetes. Health Expect. 2006;9(1):25-36.

6. Barry MJ, Edgman-Levitan S. Shared decision making - the pinnacle of patient-centered care. N Engl J Med. 2012;366(9):780-781.
7. Guilbert JJ. The World Health Report 2002 - Reducing Risks, Promoting Healthy Life. Educ Health (Abingdon). 2003;16(2):230.

8. Coulter A, Ellins J. Effectiveness of strategies for informing, educating, and involving patients. BMJ. 2007;335(7609):24-27.

9. Sekimoto M, Asai A, Ohnishi M, et al. Patients' preferences for involvement in treatment decision making in Japan. BMC Fam Pract. 2004;5:1.

10. Wong EL, Leung MC, Cheung AW, Yam CH, Yeoh EK, Griffiths S. A population-based survey using PPE-15: relationship of care aspect to patient satisfaction in Hong Kong. Int J Qual Health Care. 2011;23(4): 390-396.

11. Coulter A, Jenkinson C. European patients' views on the responsiveness of health systems and healthcare providers. Eur J Public Health. 2005;15(4):355-360.

12. Degner LF, Kristjanson LJ, Bowman D, et al. Information needs and decisional preferences in women with breast cancer. JAMA. 1997; 277(18):1485-1492.

13. Coulter A, Edwards A, Elwyn G, Thomson R. Implementing shared decision making in the NHS. Z Evid Fortbild Qual Gesundhwes. 2011; 105(4):300-304.

14. Holman H, Lorig K. Patient self-management: a key to effectiveness and efficiency in care of chronic disease. Public Health Rep. 2004; 119(3):239-243.

15. Coulter A. Patient engagement - what works? J Ambul Care Manage. 2012;35(2):80-89.

16. Légaré F, Witteman HO. Shared decision making: examining key elements and barriers to adoption into routine clinical practice. Health Aff (Millwood). 2013;32(2):276-284.

17. Hospital Authority. Hospital Authority Statistical Report 2014-2015. Available from: http://www.ha.org.hk/haho/ho/stat/HASR1415_2.pdf. Accessed March 15, 2016.

18. Wong E, Yeoh E, Lui S, Cheung A, Huang N. Patient Experience and Satisfaction Survey on Specialist Outpatient Service 2014. Available from: http://www.b27association.org/news/2014\%E5\%B9\%B4\%E5\%B0\%88 $\% \mathrm{E} 7 \% \mathrm{~A} 7 \% 91 \% \mathrm{E} 9 \% 96 \% 80 \% \mathrm{E} 8 \% \mathrm{~A} 8 \% \mathrm{BA} \% \mathrm{E} 7 \% 97 \% 85 \% \mathrm{E} 4 \% \mathrm{BA} \%$ ВА $\%$ Е7\%B6\%93\%Е9\%A9\%97\%Е5\%8F\%8A $\%$ E6\%9C\%8D\%Е5\%8 В\%99\%Е6\%BB\%BF\%Е6\%84\%8F\%Е5\%BA\%A6\%Е8\%AA\%BF\%Е 6\%9F\%A5\%E5\%A0\%B1\%E5\%91\%8A/. Accessed January 15, 2016.

19. Benbassat J, Pilpel D, Tidhar M. Patients' preferences for participation in clinical decision making: a review of published surveys. Behav Med. 1998;24(2):81-88.

20. Butow P, Maclean M, Dunn S, Tattersall M, Boyer M. The dynamics of change: cancer patients' preferences for information, involvement and support. Ann Oncol. 1997;8(9):857-863.

21. Friedberg MW, VanBusum K, Wexler R, Bowen M, Schneider EC A demonstration of shared decision making in primary care highlights barriers to adoption and potential remedies. Health Aff. 2013; 32(2):268-275.

22. Jaspers MWM, Smeulers M, Vermeulen H, Peute LW. Effects of clinical decision-support systems on practitioner performance and patient outcomes: a synthesis of high-quality systematic review findings. $J \mathrm{Am} \mathrm{Med}$ Inform Assoc. 2011;18(3):327-334.

23. Piette JD, Rosland A-M, Marinec NS, Striplin D, Bernstein SJ, Silveira MJ. Engagement with automated patient monitoring and selfmanagement support calls: experience with a thousand chronically ill patients. Med Care. 2013;51(3):216-223.

24. National Cancer Equality Initiative. The Impact of Patient Age on Clinical Decision-Making in Oncology. 2012. Available from: https:// www.gov.uk/government/uploads/system/uploads/attachment_data/ file/215155/dh_133095.pdf. Accessed April 12, 2016.

25. Russell E, Smith C. Whose health is it anyway? Enabling participation. J Epidemiol Community Health. 2003;57(10):762-763.

26. Ford S, Schofield T, Hope T. Are patients' decision-making preferences being met? Health Expect. 2003;6(1):72-80.

27. Nease RF, Brooks WB. Patient desire for information and decision making in health care decisions: the Autonomy Preference Index and the Health Opinion Survey. J Gen Intern Med. 1995;10(11):593-600. 
28. McCabe R, Khanom H, Bailey P, Priebe S. Shared decision-making in ongoing outpatient psychiatric treatment. Patient Educ Couns. 2013; 91(3):326-328.

29. Tinetti ME, Basch E. Patients' responsibility to participate in decision making and research. JAMA. 2013;309(22):2331.

30. Charles C, Gafni A, Whelan T. Decision-making in the physicianpatient encounter: revisiting the shared treatment decision-making model. Soc Sci Med. 1999;49(5):651-661.

31. Steven W, Rao C. Experience in information use making by marketing managers. J Mark Res. 2014;27(1):1-10.

32. Cioffi J. A study of the use of past experiences in clinical decision making in emergency situations. Int J Nurs Stud. 2001;38(5):591-599.

33. Huang R, Gionfriddo MR, Zhang L, Leppin AL, Ting HH, Montori VM. Shared decision-making in the People's Republic of China: current status and future directions. Patient Prefer Adherence. 2015;9: 1129-1141.

34. Elwyn G, Lloyd A, Joseph-Williams N, et al. Option Grids: shared decision making made easier. Patient Educ Couns. 2013;90(2):207-212.

35. Hospital Authority. Hospital-Based Patient Experience and Satisfaction Survey 2013. 2013. Available from: http://www.cmc.org.hk/haho/ho/ cad_bnc/HAB_P211.pdf. Accessed February 15, 2016.

36. The Department of Health. High Quality Care For All; 2008. Available from: https://www.gov.uk/government/uploads/system/uploads/ attachment_data/file/228836/7432.pdf. Accessed February 15, 2016.
37. Bernabeo E, Holmboe ES. Analysis \& commentary: patients, providers, and systems need to acquire a specific set of competencies to achieve truly patient-centered care. Health Aff. 2013;32(2):250-258.

38. Delbanco T, Berwick DM, Boufford JI, et al. Healthcare in a land called people power: nothing about me without me. Health Expect. 2001;4(3): 144-150.

39. Kennedy ADM, Sculpher MJ, Coulter A, et al. Effects of decision aids for menorrhagia on treatment choices, health outcomes, and costs: a randomized controlled trial. JAMA. 2002;288(21):2701-2708.

40. Wolf MS, Feinglass J, Thompson J, Baker DW. In search of "low health literacy": threshold vs. gradient effect of literacy on health status and mortality. Soc Sci Med. 2010;70(9):1335-1341.

41. Bogardus ST, Holmboe EJ, Jekel JF. Perils, pitfalls, and possibilities in talking about medical risk. JAMA. 1999;281(11):1037-1041.

42. Stiggelbout AM, Van der Weijden TV, De Wit MP, et al. Shared decision making: really putting patients at the centre of healthcare. Br Med J. 2012;344:e256.

43. Glass K, Wills C, Holloman C, et al. Shared decision making and other variables as correlates of satisfaction with health care decisions in a United States National Survey. Patient Educ Couns. 2012;88(1):100-105.

44. Carman KL, Dardess P, Maurer M, et al. Patient and family engagement: a framework for understanding the elements and developing interventions and policies. Health Aff. 2013;32(2):223-231.
Patient Preference and Adherence

\section{Publish your work in this journal}

Patient Preference and Adherence is an international, peer-reviewed, open access journal that focuses on the growing importance of patient preference and adherence throughout the therapeutic continuum. Patient satisfaction, acceptability, quality of life, compliance, persistence and their role in developing new therapeutic modalities and compounds to optimize

\section{Dovepress}

clinical outcomes for existing disease states are major areas of interest for the journal. This journal has been accepted for indexing on PubMed Central. The manuscript management system is completely online and includes a very quick and fair peer-review system, which is all easy to use. Visit http://www. dovepress.com/testimonials.php to read real quotes from published authors. 